\title{
Maturity Onset Diabetes of the Young due to Glucokinase, HNF1-A, HNF 1-B, and HNF4-A Mutations in a Cohort of Turkish Children Diagnosed as Type 1 Diabetes Mellitus
}

\author{
Elif Ozsu $^{\mathrm{a}}$ Filiz Mine Cizmecioglu ${ }^{\mathrm{b}}$ Gul Yesiltepe Mutlu ${ }^{\mathrm{c}}$ Aysegul Bute Yuksel ${ }^{\mathrm{d}}$ \\ Mursel Calıskan ${ }^{\mathrm{e}}$ Ahmet Yesilyurt ${ }^{\mathrm{e}}$ Sukru Hatun ${ }^{\mathrm{c}}$ \\ a Samsun Obstetrics and Children Hospital, Illkadım, Turkey; ${ }^{b}$ University of Kocaeli, School of Medicine, \\ Department of Pediatric Endocrinology and Diabetes, Izmit, Turkey; ${ }^{C}$ University of Koc, School of Medicine, \\ Department of Pediatric Endocrinology and Diabetes, İstanbul, Turkey; ${ }^{\mathrm{d}}$ Derince Research and Training Hospital, \\ Pediatric Endocrinology, Kocaeli, Turkey; ${ }^{\text {}}$ Department of Genetics, Dıskapı Yildirim Beyazit Education and \\ Research Hospital, Ankara, Turkey
}

\section{Keywords}

Monogenic diabetes $\cdot$ Childhood · Type 1 diabetes

\begin{abstract}
Background/Aims: Maturity onset diabetes of the young (MODY) is a rare condition often misdiagnosed as type 1 diabetes (T1D). The purposes of this study were: to identify any patients followed in a large Turkish cohort as T1D, with an atypical natural history, who may in fact have MODY, and to define the criteria which would indicate patients with likely MODY as early as possible after presentation to allow prompt genetic testing. Methods: Urinary C-peptide/creatinine ratio (UCPCR) was studied in 152 patients having a diagnosis of T1D for at least 3 years. Those with a UCPCR $\geq 0.2 \mathrm{nmol} / \mathrm{mmol}$ were selected for genetic analysis of the Glucokinase (GCK), Hepatocyte nuclear factor 1a (HNF1A), Hepatocyte nuclear factor $4 a$ (HNF4A), and Hepatocyte nuclear factor 1b (HNF1B) genes. This UCPCR cut-off was used because of the reported high sensitivity and specificity. Cases were also evaluated using a MODY probability calculator.
\end{abstract}

\section{KARGER}

(c) 2018 S. Karger AG, Basel

E-Mail karger@karger.com

www.karger.com/hrp
Results: Twenty-three patients from 152 participants (15.1\%) had a UCPCR indicating persistent insulin reserve. The mean age \pm SD of the patients was $13.6 \pm 3.6$ years (range $8.30-21.6)$. Of these 23 , two (8.7\%) were found to have a mutation, one with HNF4A and one with HNF1B mutation. No mutations were detected in the GCK or HNF1A genes. Conclusion: In Turkish children with a diagnosis of T1D but who have persistent insulin reserve 3 years after diagnosis, up to $9 \%$ may have a genetic mutation indicating a diagnosis of MODY.

(c) 2018 S. Karger AG, Basel

\section{Introduction}

The term "maturity onset diabetes of the young" (MODY) describes a form of diabetes that is familial, non-insulin-dependent, and occurs in patients of young age. It constitutes between one and five percent of all cases of diabetes [1]. MODY may be misdiagnosed as type 1 or type 2 diabetes mellitus $[1,2]$. 
According to the 2011 American Diabetes Association (ADA) guidelines, which were current at the time of this study, subjects with a parental history of diabetes, low insulin requirement, and negative pancreatic antibodies at the time of diagnosis should be evaluated for MODY [3]. The probability of MODY is high in such cases. However, there may sometimes be an overlap between the clinical findings of MODY and type 1 diabetes [4]. Age at diagnosis and family history have been shown to be insufficient in identifying some cases of MODY, and hence, the presence of persistent endogenous insulin, after the "honey-moon period" has ended, should also be evaluated in suspected cases $[4,5]$.

Genetic testing will be helpful in obtaining a definitive diagnosis and for the identification of affected family members. In some countries, up to $80 \%$ of MODY cases are reported to be misdiagnosed as type 1 or type 2 diabetes [5] with GCK, HNF1A, and HNF4A mutations being the most commonly seen, accounting for around $80 \%$ of all MODY cases [6]. However, such testing is also costly and of limited availability. In addition, early diagnosis and treatment are of the utmost importance for preventing potential complications so that genetic investigations should not delay treatment initiation.

Analysis of C-peptide from a venous blood sample can act as a screening test for possible cases of MODY. Cpeptide measurement is the most reliable method for evaluating beta cell function $[5,6]$. However, because Cpeptide can be easily broken down with proteases and its levels may decrease rapidly, it may not always give definitive results [6]. Specimens must therefore be taken under appropriate conditions and sent to the laboratory in a cold chain. Urinary C-peptide/creatinine ratio (UCPCR) measurement is a more stable and noninvasive method [7].

Urinary C-peptide concentration approximates to $5-10 \%$ of daily pancreatic secretion, while insulin concentration represents only $0.1 \%$ of secreted insulin in the same period. The UCPCR remains stable for $24 \mathrm{~h}$ at room temperature and for 3 days if refrigerated at up to $+4{ }^{\circ} \mathrm{C}$ without preservative. An 18\% decrease has been reported when stored for 90 days at $-20^{\circ} \mathrm{C}$. However, if stored at $-80^{\circ} \mathrm{C}$, no decrease in the UCPCR was seen and the results correlate well with 24-hour urine specimens $[6,7]$.

Diabetes classification using insulin reserve is used in persons with a clinical diagnosis for greater than 2 years. A UCPCR above $0.2 \mathrm{nmol} / \mathrm{mmol}$ is suggestive of remaining pancreatic reserve and is also safe and noninvasive. Although UCPCR $\geq 0.4 \mathrm{nmol} / \mathrm{mmol}$ may be seen up to 5 years after diagnosis in $3 \%$ of cases of type 1 diabetes, in the remaining $97 \%$ of these cases, UCPCR values are lower than this cut-off [8]. It may therefore be effective and economic to use UCPCR to select patients for MODY genetic analyses.

It is important to identify cases diagnosed with type 1 diabetes with persisting endogenous insulin secretion because this can guide the clinician in terms of the genetic analysis for identifying cases of MODY. Genetic diagnosis is important for establishing good glycemic control as the treatment modalities are different for bona fide type 1 diabetes and MODY. In MODY, low-dose sulfonylurea therapy may be effective, particularly in patients with HNF4A and HNF1A mutation, and also to avoid unnecessary insulin therapy in patients in whom GCK mutation is the etiology.

The purpose of this study was to identify cases of MODY by performing genetic analysis for the most commonly seen etiological mutations, the subjects being a cohort of Caucasian Turkish patients. All patients had been diagnosed initially with type 1 diabetes, but had persistent insulin reserves, even after years of treatment. Preliminary screening of patients using a screening cut-off of $\geq 0.2 \mathrm{nmol} / \mathrm{mmol}$ for the UCPCR, which is reported to have high sensitivity combined with high specificity [7], identified patients for further genetic analysis.

\section{Subjects and Methods}

\section{Study Population}

There were 560 patients with a clinical diagnosis of type 1 diabetes, thus excluding secondary causes of diabetes, registered with the Study Centre from 2000 to 2012. Four hundred and thirty patients having the diagnosis of diabetes for at least a 3 -year duration were assessed for regularity of clinic attendance. This resulted in 300 patients being eligible for the study and these were invited to participate in the study. Consent was obtained from parents or adolescents, with younger patients invited to assent, resulting in 152 subjects taking part in the study (see Fig. 1).

For these 152 participants, retrospective data were obtained from medical records. Patients' insulin requirements were calculated on the basis of the daily insulin dose they were receiving (IU/ $\mathrm{kg} / \mathrm{day}$ ). Age at diagnosis, duration of the disease, presence or absence of classic symptoms (osmotic symptoms such as polydipsia and polyuria and weight loss), presence of diabetic ketoacidosis, and family history encompassing at least three generations were investigated.

\section{Meal Protocol and Sample Collection}

All patients attended the clinic following an overnight fast. Patients were asked to void urine before eating the standardized meal. Subsequent to this, they had a standard breakfast, which contained $55 \%$ of carbohydrate, $30 \%$ fat, and $15 \%$ protein (Turkish breakfast bagel, cucumber, tomato, cheese, olives). The weight of carbohy- 


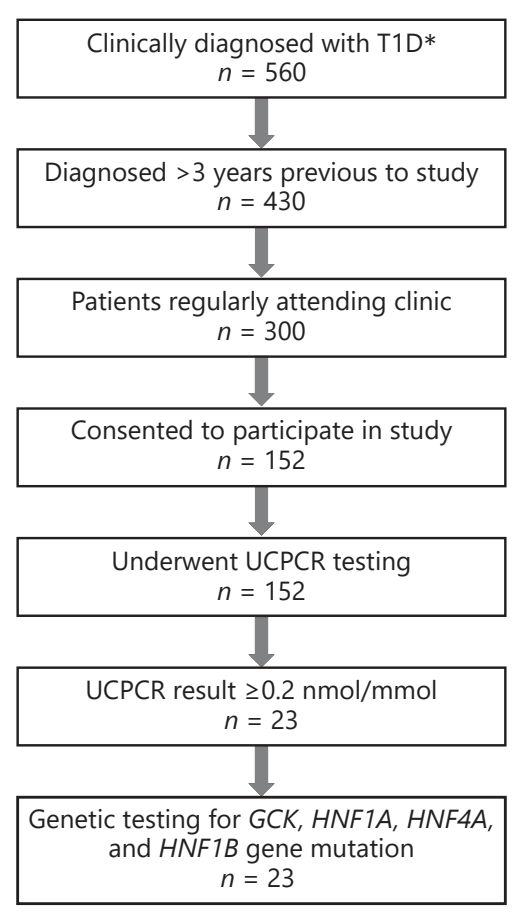

Fig. 1. This flow diagram shows the selection process for those patients who were selected to undergo genetic testing for MODYassociated gene mutations. T1D, type 1 diabetes; UCPCR, urinary $\mathrm{C}$-peptide to creatinine ratio; GCK, Glucokinase gene; HNF1A, Hepatocyte nuclear factor 1a gene; HNF4A, Hepatocyte nuclear factor $4 \mathrm{a}$ gene; HNF1B, Hepatocyte nuclear factor $1 \mathrm{~b}$ gene. ${ }^{*}$ Thus excluding patients with secondary forms of diabetes and type 2 diabetes.

drate contained in the breakfast was a minimum of $60 \mathrm{~g}$. Patients self-administered their usual insulin as appropriate for the breakfast.

Two hours following breakfast, venous samples for serum analysis for glucose, stimulated C-peptide, and $\mathrm{HbA} 1 \mathrm{c}$ were obtained. Serum samples were sent immediately to the laboratory for analysis. At the same time, $2 \mathrm{ml}$ EDTA blood sample was collected, and DNA was extracted and stored at $-80^{\circ} \mathrm{C}$ for later MODY genetic testing. Patients were asked to provide a urine sample as soon as possible after blood sample collection. Urine samples were stored at $-80^{\circ} \mathrm{C}$ until analysis.

\section{Urinary C-Peptide to Creatinine Ratio}

Postprandial UCPCR was calculated for each patient. Urinary C-peptide was analyzed using an electrochemiluminescence immunoassay (Roche E170 Cobas and 03184897 kits). The results were recorded as $\mathrm{mmol} / \mathrm{L}$. Values above $13.3 \mathrm{nmol} / \mathrm{L}$ were repeated at a dilution of $1 / 10$. Urine creatinine values were measured (Abbott Architect 3L8122-32 kits) and results were converted from $\mathrm{mg} / \mathrm{dL}$ to $\mathrm{mmol} / \mathrm{L}$ using the conversion factor 0.08842 .
The UCPCR was then calculated for all 152 patients. A ratio of $\geq 0.2 \mathrm{nmol} / \mathrm{mmol}$ was regarded as evidence of persistent insulin reserve. Confirmation was established with repeated UCPCR measurements. Molecular genetic analysis for GCK, HNF1A, HNF4A, and $H N F 1 B$ mutations was performed in subjects with a UCPCR value $\geq 0.2 \mathrm{nmol} / \mathrm{mmol}$.

\section{Blood Sample Analysis}

Serum C-peptide was measured using a chemiluminescent immunometric assay on a Siemens IMMULITE 2000 analyzer and L2KPE kits. The measurement range for this methodology is 0.1$29.0 \mathrm{ng} / \mathrm{mL}$ and the normal range for C-peptide was accepted to be $1.1-5.0 \mathrm{ng} / \mathrm{mL}$.

HbAlc measurements were performed using HPLC before 2008. Since then HbA1c has been measured using a chemiluminescence technique using Abbott Architect HbA1c kits (4P72) with a measurement range of $4.0-15.8 \%$. The laboratory upper limit of normal was taken as $6.5 \%$.

Anti-glutamic acid decarboxylase antibody (GAD) was analyzed using Euroimmun Anti-GAD ELISA (IgG) kits, standardized against WHO National Institute for Biological Standards and Control (England, 1999, reagent code 97/550). This method has a lower measurement level limit of $0.2 \mathrm{IU} / \mathrm{mL}$. GAD $\geq 10 \mathrm{IU} / \mathrm{mL}$ was regarded as positive.

To test for anti-islet cell antibody (ICA), the indirect immunofluorescence technique was used using monkey pancreas as substrate (Euroimmun Anti-islet ELISA FA1020 IgG Antibody kits). Titres of $1 / 10$ or greater were considered positive.

\section{MODY Probability Scores}

MODY probability scores were calculated with a MODY Probability Calculator (MPC) as described previously [9]. This program takes into account age at diagnosis, sex, whether or not on insulin treatment, BMI, HbA1c level, current age, and family history of diabetes, which are used to calculate a score for detecting patients who may have MODY. An MPC score $\geq 40 \%$ indicates a high likelihood of the patient actually having MODY.

\section{Molecular Genetic Analyses for GCK, HNF1A, HNF4A, and}

HNF1B mutations

Genomic DNA was isolated from the collected whole blood samples using High Pure PCR Template Preparation Kits (Roche Life Science, Indianapolis, IN, USA). All exons, the proximal promoter regions, and exon-intron boundaries of four genes, $G C K$, HNF1A, HNF4A and HNF1B, were amplified using PCR, with the use of specific primer sets. PCR was performed in a $20 \mu \mathrm{L}$ final volume containing $20 \mathrm{ng}$ of genomic DNA, $1 \mu \mathrm{L}$ of each primer, 12.5 $\mu \mathrm{L}$ PCR Master Mix (GML AG, Altendorf, Switzerland), and 0.2 $\mu \mathrm{L}$ Taq DNA polymerase (GML AG, Altendorf, Switzerland). The PCR reaction was initiated by denaturing the sample at $96^{\circ} \mathrm{C}$ for $5 \mathrm{~min}$ followed by 40 cycles of denaturation at $94^{\circ} \mathrm{C}$ for $30 \mathrm{~s}$, annealing at $60^{\circ} \mathrm{C}$ for $45 \mathrm{~s}$, and extension at $72^{\circ} \mathrm{C}$ for $45 \mathrm{~s}$. Final extension was performed at $72^{\circ} \mathrm{C}$ for $10 \mathrm{~min}$. All reactions were performed in an ABI Veriti Thermal Cycler (Applied Biosystems, Foster City, CA, USA). PCR products were cleaned using ExoSAP-IT reagent (GML AG, Altendorf, Switzerland).

The sequencing reaction was then performed on both strands using BigDye Terminator v3.1 Cycle Sequencing Kits (Applied Biosystems, Foster City, CA, USA). Sequencing products were purified using an Applied Biosystems BigDye XTerminator Purifica- 
tion Kit (Applied Biosystems, Foster City, CA, USA). Capillary electrophoresis was performed on a 3130xl Genetic Analyzer (Applied Biosystems, Foster City, CA, USA). Sequences were analyzed using Seqscape v3.1 and variant reporter v.1 (Applied Biosystems, Foster City, CA, USA) software.

\section{Interpretation of Mutations}

The mutation prediction tools MutationTaster [10], Polyphen2 [11], and SIFT [12] were used for in silico mutation analysis. Known variants reported in the scientific literature were investigated on the Human Gene Mutation Database $\left(\mathrm{HGMD}^{\circledR}\right)$ [13], Clinvar [14], Pubmed [15], and OMIM [16]. Population data for known variants were investigated from the Exome Aggregation Consortium (ExAC) [17] and 1000 Genomes Project Consortium (1000 Genomes) [18] databases. In line with the American College of Medical Genetics Standards and Guidelines [19], all variants were classified as "pathogenic," "likely pathogenic," "uncertain significance," "likely benign," or "benign."

\section{Statistical Analysis}

Descriptive statistics were calculated for all 152 patients taking part in the study using Minitab statistical software v13 (Minitab Inc., State College, PA, USA). Both descriptive and comparative statistics were calculated for each of the two groups of patients, those with a UCPCR $\geq 0.2 \mathrm{nmol} / \mathrm{mmol}$ and those with a UCPCR < $0.2 \mathrm{nmol} / \mathrm{mmol}$. Normality of distribution was tested using the Anderson Darling test. For comparison of qualitative data, the two-sample $t$ test was used. Continuous parametric data was assessed using analysis of variance (ANOVA) and presented as mean $( \pm \mathrm{SD})$, whilst nonparametric data was assessed using Mann-Whitney $\mathrm{U}$ test with data presented as median (range). Significance was assumed with $p<0.05$.

Ethical approval for the study was obtained from Kocaeli University Scientific Research Unit's ethical committee (No. 2012/145). Written informed consent was obtained from the patients' parents.

\section{Results}

Of 560 patients with a clinical diagnosis of type 1 diabetes in our records, thus excluding those with secondary causes of diabetes, 430 had had a clinical diagnosis for more than 3 years. Of these 430, 300 were attending clinic regularly. These 300 patients were invited to participate in the study and consent was obtained for 152 to do so. All 152 underwent UCPCR testing and 23 (15.1\%) patients had a UCPCR value $\geq 0.2 \mathrm{nmol} / \mathrm{mmol}$ indicating persistent insulin reserve. These 23 patients were selected for genetic analysis. Of these 23 patients, 15 were male, with a mean age of $13.7 \pm 3.2$ years (range 8.3-21 years). The clinical and laboratory characteristics of subjects with persistent insulin reserve are shown in Table 1. Two pathogenic mutations were found in the study subjects giving an incidence of $8.7 \%$ of pathogenic mutations found in the group of patients meeting the selection criteria.
For the 152 patients, consisting of 88 male and $66 \mathrm{fe}$ male patients with a median birth weight (range) of 3,300 g $(1,900-5,740)$, at initial diagnosis their median age (range) was 7.0 years $(1.0-16)$ and mean $\mathrm{HbAlc}( \pm \mathrm{SD})$ was $11.8 \%( \pm 2.9)$. Median time (range) between initial diagnosis and the study was 67 months (36-244). At the time of the study, in all 152 patients mean $\mathrm{HbAlc}( \pm \mathrm{SD})$ was $11.4( \pm 2.8)$ and median (range) BMI SD, insulin requirement, UCPCR, stimulated C-peptide, and MPC scores were 0.105 (-2.41 to 4.13$), 1.0 \mathrm{U} / \mathrm{kg} / \mathrm{day}(0.1-1.6)$, $0.011 \mathrm{nmol} / \mathrm{mmol}(<0.001-1.2), 0.1 \mathrm{ng} / \mathrm{dL}(0.01-1.57)$, and $1.9 \%(0.7-12.6)$, respectively.

When we compared the patients who had and those who did not have evidence of persistent insulin reserve for the same parameters, significant differences were found for UCPCR (median 0.47 vs. $0.006 \mathrm{nmol} / \mathrm{mmol}$; $p<0.0001$ ), stimulated c-peptide (median 0.3 vs. $0.1 \mathrm{ng} /$ $\mathrm{dL} ; p<0.0001$ ), and months between initial diagnosis and the study $(p=0.022)$. In the 23 patients who had genetic testing, the median (range) time between diagnosis and study was shorter at 54 months (37-156), while for the remainder it was 75 months (36-244). In addition, at the time of the study, in those with insulin reserve, the median $\mathrm{HbAlc}$ was significantly lower $(p=0.004)$ at $8.6 \%$ (5.8-17.0) compared to $12.0 \%(5.0-19.0)$. There was no difference between the two groups when we compared gender, birth weight, age at initial diagnosis, HbAlc at diagnosis, GAD positivity at diagnosis, or BMI SD or insulin use at the time of the study. Interestingly, there was no difference between the groups in terms of MPC score either $(p=0.66)$, with very similar median MPC scores (range) of $1.9 \%(0.7-12.0)$ and $1.9 \%(0.7-12.6)$ for the groups with and without insulin reserve, respectively. We also investigated the relationship between UCPCR and stimulated serum C-peptide in the patients undergoing genetic analysis. This showed poor correlation in our cohort, with a Spearman rho of $r_{s}=0.26$.

Two of the twenty-three patients who went forward for genetic testing were found to have significant genetic variations, both of which have been previously reported. In one patient, a heterozygous mutation was detected in the HNF4A gene (A45L; p.Ala45Leu), which causes MODY1 (Table 1 , Patient 1 ). In a second patient, a heterozygous mutation was found in $H N F 1 B$ (R165H; p.Arg165His) known to cause MODY5 (Table 1, Patient 2).

The diagnosis of Patient 1 has been revised as MODY1, even though her insulin requirement was $1.2 \mathrm{U} / \mathrm{kg} /$ day. UCPCR was $0.38 \mathrm{nmol} / \mathrm{L}, \mathrm{HbA} 1 \mathrm{c}$ at diagnosis was $11.9 \%$ $(107 \mathrm{mmol} / \mathrm{mol})$, and MPC score was $0.7 \%$. There was a maternal history of gestational diabetes during the preg- 
Table 1. Clinical and biochemical characteristics of 23 patients initially clinically diagnosed with type 1 diabetes but with persistent insulin reserve more than 3 years after presentation

\begin{tabular}{|c|c|c|c|c|c|c|c|c|c|c|c|c|}
\hline Patient & $\begin{array}{l}\text { Age at } \\
\text { diagnosis, } \\
\text { years }\end{array}$ & $\begin{array}{l}\text { Months } \\
\text { since } \\
\text { diagnosis }\end{array}$ & $\begin{array}{l}\text { HbAlc at } \\
\text { diagnosis, \% } \\
\text { (mmol/mol) }\end{array}$ & $\begin{array}{l}\text { GAD at } \\
\text { diagnosis } \\
\text { (positive or } \\
\text { negative) }\end{array}$ & $\begin{array}{l}\text { History of } \\
\text { DKA } \\
\text { (yes or no)* }\end{array}$ & $\begin{array}{l}\text { Family history of } \\
\text { diabetes for three } \\
\text { generations } \\
\text { (generations affected) }\end{array}$ & $\begin{array}{l}\text { HbAlc at } \\
\text { study, } \\
\% \\
(\mathrm{mmol} / \mathrm{mol})\end{array}$ & $\begin{array}{l}\text { Insulin } \\
\text { requirement } \\
\text { at study, } \\
\mathrm{U} / \mathrm{kg} / \text { day }\end{array}$ & $\begin{array}{l}\text { Serum } \\
\text { C-peptide at } \\
\text { study, ng/dL }\end{array}$ & $\begin{array}{l}\text { UCPCR } \\
\text { at study, } \\
\text { nmol/mmol }\end{array}$ & $\begin{array}{l}\text { MPC } \\
\text { score, } \\
\%\end{array}$ & $\begin{array}{l}\text { Gene } \\
\text { variant } \\
\text { detected }\end{array}$ \\
\hline 1 & 11 & 37 & $11.4(101.1)$ & Negative & No & No (2) & $10.5(91.3)$ & 1.2 & 0.30 & 0.38 & 0.7 & HNF4A \\
\hline 2 & 11 & 41 & $16.9(161.2)$ & Negative & Yes & Yes (3) & $5.8(39.9)$ & 0.5 & 1.00 & 0.8 & 12.0 & $H N F 1 B$ \\
\hline 3 & 9 & 47 & $13.3(121.9)$ & Negative & No & Yes (3) & $8.6(70.5)$ & 0.4 & 0.30 & 1.2 & 2.6 & Negative \\
\hline 4 & 9 & 52 & Unknown & Unknown & No & No (1) & $17.0(162.3)$ & 1.0 & Not obtained & 1.15 & 0.7 & Negative \\
\hline 5 & 10 & 54 & $17.0(162.3)$ & Unknown & No & Yes (3) & Not obtained & 1.0 & 0.10 & 1.0 & 0.7 & Negative \\
\hline 6 & 9 & 81 & $7.9(62.8)$ & Unknown & Unknown & Yes (3) & $11.2(98.9)$ & 0.8 & 0.87 & 1.0 & 0.7 & Negative \\
\hline 7 & 6 & 60 & $6.7(49.7)$ & Negative & No & No (2) & $7.4(57.4)$ & 1.0 & 0.70 & 0.9 & 1.9 & Negative \\
\hline 8 & 10 & 54 & $12.3(110.9)$ & Positive & Yes & Yes (3) & Not obtained & 1.2 & 0.60 & 0.7 & 0.7 & Negative \\
\hline 9 & 10 & 49 & $10.8(94.5)$ & Positive & No & No (2) & Not obtained & 0.58 & 1.57 & 0.59 & 6.4 & Negative \\
\hline 10 & 4.5 & 49 & $14.4(133.9)$ & Unknown & Yes & Yes (3) & $7.3(56.3)$ & 0.8 & 0.24 & 0.57 & 0.7 & Negative \\
\hline 11 & 11 & 42 & Unknown & Positive & Yes & No (2) & $10.5(91.3)$ & 1.0 & 0.20 & 0.53 & 1.9 & Negative \\
\hline 12 & 7 & 122 & $16.0(151.4)$ & Positive & Yes & Unknown & $11.8(105.5)$ & 1.4 & 0.10 & 0.47 & 1.9 & Unknown \\
\hline 13 & 4 & 43 & $11.0(96.7)$ & Positive & No & No (1) & $7.8(61.7)$ & 0.9 & 0.31 & 0.47 & 0.7 & Negative \\
\hline 14 & 16 & 69 & $20.0(195.1)$ & Negative & No & No $(2)$ & $12.7(115.3)$ & 1.0 & 0.71 & 0.45 & 0.7 & Negative \\
\hline 15 & 1 & 156 & $6.0(42.1)$ & Unknown & Yes & Yes (3) & $8.6(70.5)$ & 1.0 & 0.10 & 0.39 & 8.2 & Negative \\
\hline 16 & 14 & 40 & Unknown & Positive & Yes & No (2) & $13.6(125.1)$ & 1.2 & 0.38 & 0.30 & 4.0 & Negative \\
\hline 17 & 9 & 80 & $13.8(127.3)$ & Positive & No & Yes (3) & $7.1(54.1)$ & 0.9 & 0.15 & 0.29 & 7.2 & Unknown \\
\hline 18 & 10 & 64 & $13.0(118.6)$ & Positive & Yes & No (1) & $7.2(55.2)$ & 0.8 & 0.29 & 0.26 & 0.7 & Unknown \\
\hline 19 & 9 & 42 & $16.9(161.2)$ & Positive & Yes & No (1) & $8.4(68.3)$ & 1.0 & 0.60 & 0.25 & 1.9 & Negative \\
\hline 20 & 8 & 55 & $8.1(65.0)$ & Positive & No & Yes (3) & $13.7(126.2)$ & 0.7 & 0.20 & 0.22 & 8.0 & Negative \\
\hline 21 & 3 & 63 & $10.0(85.8)$ & Negative & Yes & No (1) & Not obtained & 0.86 & 0.20 & 0.22 & 1.9 & Negative \\
\hline 22 & 4 & 50 & $13.3(121.9)$ & Unknown & Yes & No (2) & $7.0(53.0)$ & 0.7 & 0.33 & 0.21 & 7.2 & Negative \\
\hline 23 & 10 & 62 & $7.1(54.1)$ & Negative & No & No (1) & $7.2(55.2)$ & 0.6 & Not obtained & 0.20 & 1.9 & Negative \\
\hline
\end{tabular}

Patients are shown with genetic variants detected at the top (Patient 1 and Patient 2) and then ordered by UCPCR value, highest at the top. UCPCR, urinary C-peptide to creatinine ratio; DKA, diabetic ketoacidosis; MPC, MODY probability calculator; GAD, anti-glutamic acid decarboxylase antibody; HbA1c, hemoglobin Alc; MODY, maturity onset diabetes of the young; HNF4A, Hepatocyte nuclear factor 4a gene; HNF1B, Hepatocyte nuclear factor $1 \mathrm{~b}$ gene. ${ }^{*}$ This column shows if a patient had experienced an episode or episodes of DKA at any time prior to the study. 
nancy with this subject. Her BMI at the time of the study was 18.3 (SD -0.78).

The diagnosis of Patient 2 was revised to MODY5. She had a low insulin requirement of $0.5 \mathrm{U} / \mathrm{kg} /$ day. Her MPC score was $12 \%$ and UCPCR was $0.8 \mathrm{mmol} / \mathrm{L}$. Her HbAlc level was $16.9 \%(161.2 \mathrm{mmol} / \mathrm{mol})$ at initial diagnosis. Her BMI at the time of the study was 21.4 (SD 0.22). Urogenital abnormalities were not present on examination. In contrast to Patient 1 , there was no history of maternal gestational diabetes. Of the other 21 subjects who underwent genetic analysis, only one other pregnancy was affected by gestational diabetes and one other mother was not sure. Thus, a history of gestational diabetes was found in one MODY variant and one other subject with persistent insulin reserves.

\section{Discussion}

This study confirms that cases of MODY can be misdiagnosed as type 1 diabetes in line with previous reports $[32,36]$. Two mutations were found, both of which have been reported previously, one in each of two subjects; the $H N F 4 A$ gene (A45L; Patient 1 in Table 1 ) and the HNF1B gene (R165H; Patient 2 in Table 1) were identified in two of 23 patients (8.7\%) with a disease duration of 3 years or greater and UCPCR $\geq 0.2 \mathrm{nmol} / \mathrm{mmol}$.

Since first being described, MODY has led to the revision, and in some cases a change of diagnosis, in many patients diagnosed initially with type 1 diabetes, following appropriate genetic analysis [20-22]. However, because of the huge numbers of patients with type 1 diabetes, it is not feasible to genetically re-test all of them, in light of the description of MODY. Therefore, selection of patients for genetic analysis is dependent on meeting a set of criteria. In clinical terms, criteria recommended for selection of patients for genetic analysis include: pancreatic autoantibody negativity, a low HbAlc level, low insulin requirement, and a positive family history.

Gandica et al. [23] employed these clinical diagnostic criteria in determining monogenic diabetes among cases initially diagnosed as type 1 diabetes and performed genetic analysis on selected patients meeting these criteria. Fifty-eight patients (6.2\%) were identified from among 934 patients using these criteria. GCK mutation was found in four cases and HNF1A mutation in one, giving an incidence of $8.6 \%$. This incidence rate is remarkably similar to that found in our subjects, although we did not find any mutations in the GCK gene. Other important findings of this study include similar $\mathrm{HbAlc}$ levels, age at diagnosis, and the past or family history of autoimmune disorders between patients initially diagnosed with type 1 diabetes but subsequently diagnosed with MODY and patients with type 1 diabetes [23].

The mixed meal tolerance test is the gold standard to determine endogenous insulin secretion in cases with type 1 diabetes. However, stimulated, 90-min blood C-peptide level measurement has also been employed to evaluate endogenous insulin-secreting reserve [7]. Previous studies have shown that UCPCR correlated with stimulated Cpeptide measurements [6], although this was not the case in our patients, which may be due to differences in patient characteristics, as Jones et al. [6] investigated patients diagnosed after the age of 30 years. We found significant differences between the groups of patients with and without reserve for both UCPCR and stimulated C-peptide. UCPCR with a sufficiently sensitive cut-off seems to have good discrimination in screening for patients for further genetic testing for MODY. This has previously been reported by the Exeter group [7]. Given that UCPCR is less invasive, requiring only a urine sample collection, and easier to perform and handle, stimulated C-peptide testing may not be necessary in future similar studies when screening patients with diabetes who are suspected of having MODY rather than type 1 diabetes.

At a level of 0.53 , UCPCR has been determined to be $71 \%$ sensitive and $97 \%$ specific for showing endogenous insulin secretion. UCPCR is therefore a good alternative to the mixed meal tolerance test, being easier to perform and reliable. However, reserves may persist for years in cases of progressive autoimmune diabetes, such as lateonset type 1 diabetes. Genetic analysis of our patients with reserves and low insulin requirements but with antibody positivity revealed no cases of MODY, and diabetes types overlap with one another. Reserve assessment is not appropriate in newly diagnosed cases $[6,7]$.

Yılmaz Ağladıoğlu et al. [24] used UCPCR to differentiate MODY from type 1 diabetes in a pediatric group of patients diagnosed at least 2 years earlier. They reported that at a level of $0.22 \mathrm{nmol} / \mathrm{mmol}$, UCPCR exhibited 96.3\% sensitivity and $85.7 \%$ specificity for identifying cases of MODY. UCPCR was also used to differentiate MODY from type 1 diabetes in a study by Besser et al. [7]. Values of $0.2 \mathrm{nmol} / \mathrm{mmol}$ or above were shown to be $97 \%$ sensitive and $96 \%$ specific for differentiating HNF1A and HNF4A cases from type 1 diabetes [7]. We adopted the UCPCR value used by this study because of its high sensitivity combined with high specificity $[24,25]$.

In a further study, UCPCR was used at a threshold of $0.7 \mathrm{nmol} / \mathrm{mmol}$ for the differentiation of non-type $1 \mathrm{dia}$ - 
betes cases with a sensitivity of $59 \%$ and a specificity of $91 \%$ in cases diagnosed more than 2 years previously [26]. Thanabalasingham et al. [27] performed HNF1A and HNF4A sequencing in 20/247 (8.1\%) patients with clinically defined type 1 diabetes who were diagnosed at $\leq 45$ years, with a disease duration of 3 years or greater, and significant residual $\beta$-cell function defined as glucagon stimulation test (GST) increment $\geq 0.2 \mathrm{nmol} / \mathrm{L}$, random C-peptide $\geq 0.2 \mathrm{nmol} / \mathrm{L}$ with GST $0.1-0.2 \mathrm{nmol} / \mathrm{L}$, or GST declined and random C-peptide $\geq 0.2 \mathrm{nmol} / \mathrm{L}$. They found two of twenty patients (10\%) with HNF1A mutations. An overall prevalence of $0.8 \%$ for MODY was reported among patients with clinically labeled type 1 diabetes. However, the yield ratio was increased to $10 \%$ when the selection criteria were used. This result is also compatible with our incidence rate of $8.7 \%$. Thanabalasingham et al. [27] also performed HNF1A and HNF4A sequencing in $80 / 277$ clinically defined type 2 diabetes cases who were diagnosed $\leq 45$ years with positive C-peptide and negative GAD antibody. In these cases, they found ten and two mutations in the HNF1A and HNF4A genes, respectively. Overall prevalence was $4.3 \%$, which increased to $15 \%$ when the selection criteria were used [27].

HNF1A variant (MODY3) was diagnosed in $10 \%$ of Danish patients being monitored for type 1 diabetes, with diabetes in first-degree relatives and selected due to their being lower-risk than the HLA tissue group with antiGAD antibodies positive in one case. Autoantibody positivity was reported in $1 \%$ of cases diagnosed as MODY [28]. In another study, HNF1A mutation was described in $7 \%$ of antibody-negative type 1 diabetes cases [29]. All these studies demonstrate the extent to which insulin reserves can act as a guide in patient selection [25,27].

Various atypical characteristics, including an increased BMI, anti-GAD positivity, and absence of family history, have also been observed in MODY patients in some recent publications [30-33]. Neither of the patients who had genetic variants in our cohort had unusual BMI. Patient 1 with the HNF4A mutation was lean (BMI SD -0.78 ), in keeping with previous reports of the phenotype associated with MODY 1 [34], but not exceptionally so, whilst Patient 2 with the HNF1B mutation had a normal BMI for age (BMI SD 0.22) at the time of study. In a study from Germany involving children and adults, anti-GAD positivity was detected in 22\% of MODY cases [35]. A family history over three generations was present in 9 of $23(39.1 \%)$ cases in our study and one of the patients with a detected mutation. Autoantibody levels were negative at diagnosis in both our two mutation-positive cases. Our cases' MODY probability scores were 0.7 and $12 \%$. None

UCPCR in Children with Type 1 Diabetes of the 23 patients selected on the basis of UCPCR level for MODY genetic testing had an MPC score above $12 \%$. This may be because all of them had started insulin immediately after diagnosis, which has the effect of markedly reducing MPC scores, particularly in a pediatric population. Indeed, one of the mutation-positive cases had presented with diabetic ketoacidosis, which demands urgent treatment with insulin. At the time of the study, all patients were still using insulin routinely, despite that this may have been inappropriate, but this has the effect of again skewing the MPC scores down. If we had used the MPC score in isolation, neither of our mutation-positive patients would have gone forward for genetic analysis.

Even in the UK, where prevalence studies have been performed and distributions by region are clear, the number of MODY cases diagnosed are only $10-20 \%$ of the expected figure. Thus $80 \%$ of cases of MODY are still undiagnosed. These patients, if misdiagnosed as type 1 diabetes, are therefore taking unnecessary insulin injections with accompanying safety issues and not receiving treatment appropriate for MODY [30-33]. One of the additional benefits of identifying patients with MODY is that insulin is ineffective in controlling their diabetes in some forms of MODY and an effective alternative treatment can be given. Although HNF1B (Patient 2) mutations still require insulin therapy, both $\mathrm{HNF} 1 \mathrm{~A}$ and $\mathrm{HNF} 4 \mathrm{~A}$ ( $\mathrm{Pa}-$ tient 1) are responsive, especially in the early stages of their diabetes, to treatment with sulfonylurea but may eventually require insulin therapy to be restarted [34]. It has been suggested that the replacement of multiple daily injections of insulin with therapy using sulfonylurea tablets may have the added benefit of increasing treatment adherence. Patient 1 was unfortunately lost to follow-up after the study. The patient has now been recalled to clinic and is currently undergoing a trial of sulfonylurea therapy, but may require insulin to be added back in as they get older.

A predictive model for identifying MODY cases among patients initially diagnosed with type 1 diabetes was reported in the Czech Republic in 2016 [36]. Of 557 cases, 53 families with two or more individuals diagnosed with diabetes were selected for GCK, HNF1A, HNF4A, and INS gene analysis. Diagnosis of 24 families was changed from type 1 diabetes to MODY. GCK mutations were detected in fourteen families, HNFA1 in nine families, and INS in one family, respectively. In this study, family history was shown to be the most important clinical predictor for determining the probability of MODY. In our study, there were eight families with three generations diagnosed with diabetes and UCPCR $>0.2 \mathrm{nmol} / \mathrm{mmol}$. However, only 
one of these families was shown to have a pathogenic MODY-causing mutation, $H N F 1 B$, while there was no family history in the patient found to have HNF4A mutation.

The main limitation in our study was that we did not analyze the INS gene. This has been reported to account for around $4 \%$ of MODY cases. Therefore, it is possible that one of 23 patients (approximately 4\%) who met the inclusion criteria for genetic analysis may be carrying mutations in the INS gene but erroneously retain the diagnosis of type 1 diabetes.

In conclusion, our findings confirm and extend the findings that UCPCR can be used as a screening technique to detect patients initially diagnosed with type 1 diabetes with long-standing, post-diagnosis insulin re- serve who may actually have MODY. Our prevalence figure in a pediatric population of Turkish ethnicity is broadly in line with figures reported from other populations. Given that up to $80 \%$ of MODY patients may be misdiagnosed, UCPCR is a practical technique for identifying patients who should have further genetic testing, thus making the screening more cost-effective. This will prevent unnecessary and inappropriate treatment in a number of MODY patients currently misdiagnosed as type 1 diabetes.

\section{Disclosure Statement}

The authors report that there are no conflicts of interest.

\section{References}

1 Tattersall RB, Fajans SS, Arbor A. A difference between the inheritance of classical juvenile-onset and maturity-onset type diabetes of young people. Diabetes. 1975 Jan;24(1): 44-53.

2 Hattersley A, Bruining J, Shield J, Njolstad P, Donaghue KC. The diagnosis and management of monogenic diabetes in children and adolescents. Pediatr Diabetes. 2009 Sep;10(12 Suppl 12):33-42.

3 American Diabetes Association Diagnosis and classification of diabetes mellitus. Diabetes Care. 2011;34 Supplement_1:62-9.

4 Amed S, Dean HJ, Panagiotopoulos C, Sellers EA, Hadjiyannakis S, Laubscher TA, et al. Type 2 diabetes, medication-induced diabetes, and monogenic diabetes in Canadian children: a prospective national surveillance study. Diabetes Care. 2010 Apr;33(4):786-91.

5 Rubio-Cabezas O, Hattersley AT, Njølstad PR, Mlynarski W, Ellard S, White N, et al.; International Society for Pediatric and Adolescent Diabetes. ISPAD Clinical Practice Consensus Guidelines 2014. The diagnosis and management of monogenic diabetes in children and adolescents. Pediatr Diabetes. 2014 Sep;15(S20 Suppl 20):47-64.

6 Jones AG, Besser RE, McDonald TJ, Shields BM, Hope SV, Bowman P, et al. Urine C-peptide creatinine ratio is an alternative to stimulated serum C-peptide measurement in lateonset, insulin-treated diabetes. Diabet Med. 2011 Sep;28(9):1034-8.

7 Besser RE, Shepherd MH, McDonald TJ, Shields BM, Knight BA, Ellard S, et al. Urinary C-peptide creatinine ratio is a practical outpatient tool for identifying hepatocyte nuclear factor 1-\{alpha\}/hepatocyte nuclear factor 4 -\{alpha\} maturity-onset diabetes of the young from long-duration type 1 diabetes. Diabetes Care. 2011 Feb;34(2):286-91.
8 Palmer JP, Fleming GA, Greenbaum CJ, Herold KC, Jansa LD, Kolb H, et al. C-peptide is the appropriate outcome measure for type 1 diabetes clinical trials to preserve beta-cell function: report of an ADA workshop, 21-22 October 2001 [Erratum in: Diabetes. 2004 Jul; 53(7):1934]. Diabetes. 2004 Jan;53(1):250-64.

9 Shields BM, McDonald TJ, Ellard S, Campbell MJ, Hyde C, Hattersley AT. The development and validation of a clinical prediction model to determine the probability of MODY in patients with young-onset diabetes. Diabetologia. 2012 May;55(5):1265-72.

10 Schwarz JM, Cooper DN, Schuelke M, Seelow D. MutationTaster2: mutation prediction for the deep-sequencing age. Nat Methods. 2014 Apr;11(4):361-2.

11 Adzhubei IA, Schmidt S, Peshkin L, Ramensky VE, Gerasimova A, Bork P, et al. A method and server for predicting damaging missense mutations. Nat Methods. 2010 Apr; 7(4):248-9.

12 Choi Y, Sims GE, Murphy S, Miller JR, Chan AP. Predicting the functional effect of amino acid substitutions and indels. PLoS One. 2012; 7(10):e46688.

13 Stenson PD, Ball EV, Mort M, Phillips AD, Shiel JA, Thomas NS, et al. Human Gene Mutation Database (HGMD): 2003 update. Hum Mutat. 2003 Jun;21(6):577-81.

14 Landrum MJ, Lee JM, Benson M, Brown G, Chao C, Chitipiralla S, et al. ClinVar: public archive of interpretations of clinically relevant variants. Nucleic Acids Res. 2016 Jan; 44(D1):D862-8.

15 PubMed Health [Internet]. Bethesda (MD): National Library of Medicine (US); [updated 2011 Jan 1; cited 2011 Jan 6]. Available from: http://www.ncbi.nlm.nih.gov/pubmedhealth/
16 Online Mendelian Inheritance in Man. $\mathrm{OMIM}^{\circledR}$. McKusick-Nathans Institute of Genetic Medicine, Johns Hopkins University (Baltimore, MD), \{date\}. World Wide Web URL: http://omim.org/

17 Exome Aggregation Consortium (ExAC). Cambridge, MA (URL: http://exac.broadinstitute.org)

18 The 1000 Genomes Project Consortium:A global reference for human genetic variation. Nature. 2015 Oct;526:68-74.

19 Richards S, Aziz N, Bale S, et al. Standards and Guidelines for the Interpretation of Sequence Variants: A Joint Consensus Recommendation of the American College of Medical Genetics and Genomics and the Association for Molecular Pathology. Genet Med. 2015 May; 17(5):405-24.

20 Murphy R, Ellard S, Hattersley AT. Clinical implications of a molecular genetic classification of monogenic beta-cell diabetes. Nat Clin Pract Endocrinol Metab. 2008 Apr;4(4):200-13.

21 Fajans SS, Bell GI, Polonsky KS. Molecular mechanisms and clinical pathophysiology of maturity-onset diabetes of the young. $\mathrm{N}$ Engl J Med. 2001 Sep;345(13):971-80.

22 Hattersley AT. Maturity-onset diabetes of the young: clinical heterogeneity explained by genetic heterogeneity. Diabet Med. 1998 Jan; 15(1):15-24.

23 Gandica RG, Chung WK, Deng L, Goland R, Gallagher MP. Identifying monogenic diabetes in a pediatric cohort with presumed type 1 diabetes. Pediatr Diabetes. 2015 May;16(3): 227-33.

24 Yılmaz Agladioglu S, Sagsak E, Aycan Z. Urinary C-Peptide/Creatinine Ratio Can Distinguish Maturity-Onset Diabetes of the Young from Type 1 Diabetes in Children and Adolescents: A Single-Center Experience. Horm Res Paediatr. 2015;84(1):54-61. 
25 Hope SV, Jones AG, Goodchild E, Shepherd M, Besser RE, Shields B, et al. Urinary C-peptide creatinine ratio detects absolute insulin deficiency in Type 2 diabetes. Diabet Med. 2013 Nov;30(11):1342-8.

26 Besser RE, Shields BM, Hammersley SE, Colclough K, McDonald TJ, Gray Z, et al. Home urine C-peptide creatinine ratio (UCPCR) testing can identify type 2 and MODY in pediatric diabetes. Pediatr Diabetes. 2013 May; 14(3):181-8.

27 Thanabalasingham G, Pal A, Selwood MP, Dudley C, Fisher K, Bingley PJ, et al. Systematic assessment of etiology in adults with a clinical diagnosis of young-onset type 2 diabetes is a successful strategy for identifying maturity-onset diabetes of the young. Diabetes Care. 2012 Jun;35(6):1206-12.

28 Møller AM, Dalgaard LT, Pociot F, Nerup J, Hansen T, Pedersen O. Mutations in the hepatocyte nuclear factor-1alpha gene in Caucasian families originally classified as having Type I diabetes. Diabetologia. 1998 Dec; 41(12):1528-31.
29 Kawasaki E, Sera Y, Yamakawa K, Abe T, Ozaki M, Uotani S, et al. Identification and functional analysis of mutations in the hepatocyte nuclear factor-1alpha gene in anti-islet autoantibody-negative Japanese patients with type 1 diabetes. J Clin Endocrinol Metab. 2000 Jan;85(1):331-5.

30 McDonald TJ, Colclough K, Brown R, Shields $B$, Shepherd M, Bingley $P$, et al. Islet autoantibodies can discriminate maturity-onset diabetes of the young (MODY) from Type 1 diabetes. Diabet Med. 2011 Sep;28(9):1028-33.

31 Shields BM, Hicks S, Shepherd MH, Colclough K, Hattersley AT, Ellard S. Maturityonset diabetes of the young (MODY): how many cases are we missing? Diabetologia. 2010 Dec;53(12):2504-8.

32 Shepherd M, Ellis I, Ahmad AM, Todd PJ, Bowen-Jones D, Mannion G, et al. Predictive genetic testing in maturity-onset diabetes of the young (MODY). Diabet Med. 2001 May; 18(5):417-21.
33 Porter JR, Rangasami JJ, Ellard S, Gloyn AL, Shields BM, Edwards J, et al. Asian MODY: are we missing an important diagnosis? Diabet Med. 2006 Nov;23(11):1257-60.

34 McDonald TJ, Ellard S. Maturity onset diabetes of the young: identification and diagnosis. Ann Clin Biochem. 2013 Sep;50(Pt 5):403-15.

35 Schober E, Rami B, Grabert M, Thon A, Kapellen $\mathrm{T}$, Reinehr T, et al.; DPV-Wiss Initiative of the German Working Group for Paediatric Diabetology and. Phenotypical aspects of maturity-onset diabetes of the young (MODY diabetes) in comparison with Type 2 diabetes mellitus (T2DM) in children and adolescents: experience from a large multicentre database. Diabet Med. 2009 May;26(5):46673.

36 Petruzelkova L, Dusatkova P, Cinek O, Sumnik Z, Pruhova S, Hradsky O, et al. Substantial proportion of MODY among multiplex families participating in a Type 1 diabetes prediction. Diabet Med. 2016 Dec;33(12):1712-6. 